Gut, 1987, 28, 907-911

Clinical trial

\title{
Tripotassium dicitrato bismuthate (TDB) versus two different dosages of cimetidine in the treatment of resistant duodenal ulcers
}

\author{
G BIANCHI PORRO, F PARENTE, AND M LAZZARONI \\ From the Gastrointestinal Unit, L Sacco Hospital, Milan, Italy
}

SUMMARY The use of tripotassium dicitrato bismuthate (TDB) has been suggested recently for cimetidine resistant duodenal ulcers. This study compares the efficacy of TDB with two different cimetidine dosages in the treatment of duodenal ulcer patients who failed to respond to an eight week therapy with $\mathrm{H}_{2}$-blockers. Fifty two patients ( 40 men, 12 women) were randomly allocated to one of the following three oral regimens: (1) TDB $120 \mathrm{mg}$ qid, (2) cimetidine $400 \mathrm{mg}$ tid, (3) cimetidine $400 \mathrm{mg}$ with meals plus $800 \mathrm{mg}$ at bedtime. Endoscopy was carried out after four weeks; if the ulcer had not healed patients continued with the same treatment for a further four week period when they were endoscopically reassessed. After four weeks similar percentages of ulcer healing were registered in the two cimetidine schedules (39\% with $1 \cdot 2 \mathrm{~g}$ and $44 \%$ with $2 \mathrm{~g}$ ), whereas TDB resulted in a significantly higher healing rate $(82 \%)$ compared with cimetidine $1 \cdot 2 \mathrm{~g}(\mathrm{p}=0 \cdot 01)$ and with cimetidine $2 \mathrm{~g}(\mathrm{p}=0 \cdot 025)$. After eight weeks the cumulative percentages of healing were $65 \%$ on cimetidine $1.2 \mathrm{~g}, 75 \%$ on cimetidine $2 \mathrm{~g}$, and $94 \%$ on TDB (TDB $v$ cimetidine $1 \cdot 2 \mathrm{p}=$ $0 \cdot 042$ ). These results confirm previous data that resistant duodenal ulcers are more responsive to an agent which strengthens the mucosal defences than to antisecretory compounds.

A four week treatment with cimetidine or ranitidine usually heals $70-80 \%$ of duodenal ulcers. ${ }^{12}$ Those remaining unhealed can be cured simply by continuing the therapy for another month $;^{3}$ even after eight weeks, however, a small proportion of patients may be expected to remain unhealed, so appearing to be 'resistant' to these compounds.

The most appropriate method of medical management for such patients has not been well established as yet. Three different options may be considered: first, the current $\mathrm{H} 2$-blocker regimen can be continued unchanged for several months; ${ }^{4}$ second, the dosage of H2-blocker can be augmented in the attempt to improve the control of both day and night time gastric acid secretion; 5 third, the antisecretory drug can be substituted for one exerting a mainly cytoprotective action. ${ }^{67}$

Address for correspondence: Prof G Bianchi Porro, Gastrointestinal Unit, L Sacco Hospital, 20157 Milano, Via G B Grassi, 74, Italy.

Received for publication 21 November 1986
The validity of these three different approaches has never been evaluated in a single controlled trial. We have therefore undertaken a randomised controlled study to compare the efficacy of two different doses of cimetidine ( 1.2 and $2 \mathrm{~g}$ daily respectively) with that of tripotassium dicitrato bismuthate (TDB) tablets in the healing of duodenal ulcers resistant to an eight week treatment with cimetidine $1.2 \mathrm{~g}$ or ranitidine $300 \mathrm{mg}$ a day.

\section{Methods}

PATIENTS

The initial recruitment was made from September 1984 to March 1986 among outpatients with endoscopically proven duodenal ulcer who underwent the endoscopic control in our Unit after an eight week course of H2-blockers. Patients with unhealed ulcer and whose drug compliance was judged to be good by one examiner were considered eligible for the study. Fifty-two patients ( 40 men and 12 women) who failed 
to respond to an eight week course of cimetidine $1.2 \mathrm{~g}$ or ranitidine $300 \mathrm{mg} /$ day were enrolled; 41 were selected from the group of patients attending our department for ulcer disease, the remainder from duodenal ulcer patients referred to our Centre for the endoscopic follow up.

The largest ulcer diameter was not less than $5 \mathrm{~mm}$ and the patients did not have active bleeding, pyloric stenosis, concomitant gastric ulcer, previous gastric surgery, concurrent treatment with ulcerogenic drugs or any serious chronic disease which might influence the outcome of therapy. Pregnancy or lactation were also contraindications to enter the trial.

At the initial endoscopy the ulcer size was assessed by measuring its longest diameter with open standard biopsy forceps after pharmacological duodenal hypotonisation. Fasting serum pepsinogen I (Sorin Biomedica, Saluggia, Italy) and gastrin (Becton Dickinson, Orangeburg, New York) levels, basal acid output (BAO) and peak acid output (PAO), the latter after stimulation with pentagastrin $6 \mu \mathrm{g} / \mathrm{kg}$, were determined in all patients before treatment. Detailed information on duration and age of onset of dyspeptic symptoms, family history of peptic ulcer, previous ulcer complications and social habits were collected on the same occasion from each patient.

After giving informed verbal consent, patients were allocated according to a randomisation list for 60 subjects, to one of the following three oral regimens: (1) TDB $480 \mathrm{mg} /$ day (one chewable tablet half an hour before the three main meals and one at bedtime); (2) cimetidine $1.2 \mathrm{~g} /$ day ( $400 \mathrm{mg}$ every eight hours); (3) cimetidine $2 \mathrm{~g}$ /day (400 mg with meals plus $800 \mathrm{mg}$ at bedtime). Therapy began within five days of initial endoscopy and was continued for four weeks.

All patients were given commercially available antacid tablets (Maalox) to be taken when necessary for relief of pain. They were also instructed to daily record on a diary card both their pain episodes and the number of antacid tablets consumed. No dietary restrictions or modifications concerning smoking habits were prescribed.

Patients were seen by a physician after two and four weeks to evaluate symptoms, antacid consumption and compliance, the latter by counting the unused tablets returned at each visit by the patient. Within five days of completing the four week course of therapy, endoscopy was repeated by the same experienced operator who did the first examination; he was unaware of the patient treatment. If healing had occurred the study was ended; if not, the patient continued the same regimen for another four weeks and was then reassessed by endoscopy. If at the end of eight weeks the ulcer had not healed the patient was withdrawn from the trial.
Healing was defined as the complete disappearance of the ulcer crater; the presence of duodenitis with or without erosion did not affect the assessment of healing.

Statistical analysis of the results was carried out by means of $\chi^{2}$ test, Fisher's exact test and Student's $t$ test for paired and unpaired samples as appropriate. Differences with $p$ value less than 0.05 were considered significant.

\section{Results}

Of 52 patients who entered the trial, 18 received cimetidine $1.2 \mathrm{~g} /$ day, 17 cimetidine $2.0 \mathrm{~g} /$ day and 17 TDB. The characteristics of these patients are reported in Tables 1 and 2.

Mean age, sex ratio, mean duration and age of onset of dyspeptic symptoms, family history of peptic ulcer, alcohol and daily cigarettes consumption and previous H2-blocker therapy of the three groups were comparable (Table 1). They also did not differ significantly with respect to BAO and PAO values, fasting serum gastrin and pepsinogen I (PG I) concentrations and their longest ulcer diameter (Table 2).

One patient on cimetidine $2 \mathrm{~g}$ failed to attend the four week follow up endoscopy and one on cimetidine $1.2 \mathrm{~g}$, unhealed after the first month, defaulted before completing the second month of treatment because lack of compliance.

Endoscopic evaluation after four weeks showed that ulcer healing occurred in $39 \%(7 / 18)$ of patients receiving cimetidine $1.2 \mathrm{~g}$, in $44 \%(7 / 16)$ of those receiving cimetidine $2 \mathrm{~g}$ and in $82 \%(14 / 17)$ of those treated with TDB. The healing rate on TDB appeared to be significantly higher as compared with both that on cimetidine $1.2 \mathrm{~g}(\mathrm{p}=0.01)$ and that on cimetidine $2 \mathrm{~g}(\mathrm{p}=0.025)$ (Table 3). After eight

Table 1 Characteristics of patients at trial entry

\begin{tabular}{|c|c|c|c|}
\hline \multirow[b]{2}{*}{ Patients (n) } & \multicolumn{2}{|c|}{$\operatorname{Cim} 1 \cdot 2 \mathrm{~g} \operatorname{Cim} 2 \mathrm{~g}$} & \multirow{2}{*}{$\frac{T D B}{17}$} \\
\hline & 18 & 17 & \\
\hline Sex: male $(n)$ & 12 & 15 & 13 \\
\hline Mean age (years) $\pm S D$ & $43 \pm 13$ & $38 \pm 11$ & $43 \pm 12$ \\
\hline $\begin{array}{l}\text { Duration of dyspeptic symptoms } \\
\text { (months), mean } \pm \text { SD }\end{array}$ & $119 \pm 80$ & $116 \pm 63$ & $129 \pm 67$ \\
\hline (years), mean $\pm \mathrm{SD}$ & $34 \pm 13$ & $29 \pm 11$ & $33 \pm 12$ \\
\hline Family history of peptic ulcer ( $\%)$ & $33 \cdot 3$ & $35 \cdot 3$ & $41 \cdot 1$ \\
\hline Snıokers $(\%)$ & $77 \cdot 7$ & $70 \cdot 6$ & $64 \cdot 7$ \\
\hline$\geqslant 15$ cigarettes $/$ day $(\%)$ & $66 \cdot 7$ & $52 \cdot 9$ & $47 \cdot()$ \\
\hline $\begin{array}{l}\quad(\geqslant 50 \mathrm{~g} / \text { day }) \\
\text { Previous } \mathrm{H}_{2} \text {-blocker therapy: }\end{array}$ & $33 \cdot 3$ & $35 \cdot 3$ & $23 \cdot 5$ \\
\hline $\begin{array}{l}\text { cimetidine } 1 \cdot 2 \mathrm{~g} / \text { day }(\mathrm{n}) \\
\text { ranitidine } 3(0) \mathrm{mg} / \text { day }(\mathrm{n})\end{array}$ & $\begin{array}{r}13 \\
5\end{array}$ & $\begin{array}{r}12 \\
5\end{array}$ & $\begin{array}{r}14 \\
3\end{array}$ \\
\hline
\end{tabular}


Table 2 Characteristics of patients at trial entry

\begin{tabular}{|c|c|c|c|}
\hline & $\operatorname{Cim} 1.2 \mathrm{~g}$ & Cim $2 g$ & $T D B$ \\
\hline $\mathrm{BAO}\left(\mathrm{mmol} \mathrm{H}^{+} / \mathrm{h}\right)$, mean $\pm \mathrm{SD}$ & $8 \cdot 4 \pm 5 \cdot 8$ & $11 \cdot 6 \pm 9 \cdot 2$ & $8 \cdot 6 \pm 6 \cdot 3$ \\
\hline $\operatorname{PAO}\left(\mathrm{mmol} \mathrm{H}^{+} / \mathrm{h}\right)$, mean $\pm \mathrm{SD}$ & $47 \cdot 8 \pm 12 \cdot 5$ & $48 \cdot 2 \pm 16 \cdot 0$ & $47 \cdot 1 \pm 18 \cdot 1$ \\
\hline $\begin{array}{l}\text { Serum fasting gastrin }(\mathrm{pg} / \mathrm{ml}) \text {, } \\
\text { mcan } \pm S D\end{array}$ & $55 \cdot 5 \pm 22 \cdot 4$ & $45 \cdot 4 \pm 14 \cdot 2$ & $54 \cdot 6 \pm 17 \cdot 0$ \\
\hline $\begin{array}{l}\text { Serum fasting PG I (ng/ml), } \\
\text { mean } \pm S D\end{array}$ & $108 \cdot 0 \pm 24 \cdot 3$ & $109 \cdot 1 \pm 39 \cdot 7$ & $111 \cdot 2 \pm 35 \cdot 0$ \\
\hline $\begin{array}{l}\text { Longest ulcer diameter }(\mathrm{mm}) \text {, } \\
\text { mcan } \pm S D\end{array}$ & $6 \cdot 3 \pm 1 \cdot 4$ & $6 \cdot 8 \pm 2 \cdot 6$ & $6 \cdot 2 \pm 1 \cdot 6$ \\
\hline
\end{tabular}

weeks treatment the cumulative percentages of healing were $65 \%$ on cimetidine $1.2 \mathrm{~g}, 75 \%$ on cimetidine $2 \mathrm{~g}$ and $94 \%$ on TDB. There was a statistically significant difference between TDB and cimetidine $1.2 \mathrm{~g}$ cure rate $(p=0.042)$, while the difference between TDB and cimetidine $2 \mathrm{~g}$, although numerically obvious, did not reach statistical significance. Computation of the $95 \%$ confidence intervals for the difference in the eight week healing rates between the latter two drugs ranged from $49 \%$ in favour of TDB to $11 \%$ in favour of cimetidine $2 \mathrm{~g}$.

Tripotassium dicitrato bismuthate treated patient showed a significant decrease in antacids consumption during the first four weeks of therapy in parallel with the reduction in epigastric pain (Figure).

Conversely, the proportion of symptomatic patients as well as the antacid intake did not significantly modify during the course of the first month of therapy in both H2-blockers group (Figure). Compliance was good and similar in the three treatment groups (percentages of drugs consumed among patients who completed the trial were never less than $80 \%$ ). No relevant side effects were observed with the three treatments although a reversible brown colouration of the tongue and stools occurred in most patients on TDB.

\section{Discussion}

An agreement has not been reached yet on which duodenal ulcer should be considered resistant to $\mathrm{H} 2-$ blockers; the definitions by various authors include the following: (a) persistence of duodenal ulceration after three months of treatment with cimetidine $1 \mathrm{~g}$ daily; ${ }^{4}$ (b) failure of duodenal ulcer to heal in six weeks on cimetidine $1 \mathrm{~g}$ a day; ${ }^{89}$ (c) decrease by less than $25 \%$ of the longest ulcer diameter within four weeks on cimetidine $1 \mathrm{~g}$ daily; ${ }^{6}(\mathrm{~d})$ duodenal ulcer size unchanged after eight weeks' therapy with cimetidine $1 \mathrm{~g}$ or ranitidine $300 \mathrm{mg}$ daily. ${ }^{7011}$ In the present study we have defined 'resistant to $\mathrm{H} 2$ blockers' an ulcer still present after eight weeks treatment with cimetidine $1.2 \mathrm{~g}$ or ranitidine $300 \mathrm{mg}$ daily and with its longest diameter not less than $5 \mathrm{~mm}$. Such a definition takes into account both the usual maximal length of short term antiulcer trials and the lack of knowledge, in some patients, of the initial ulcer size due to the fact that the first diagnosis was not always established in our unit. For the same reason, the total ulcer population from which this series was recruited could not be determined; however, a measure of the magnitude of refractory duodenal ulcer as a clinical problem in the population under study can be drawn from the analysis of the short term antiulcer controlled studies involving $\mathrm{H} 2$ blockers done in our unit in the last few years.

Pooled results of the different trials, ${ }^{12-15}$ show that the mean frequency of refractoriness to an eight week treatment with cimetidine or ranitidine is $11 \%$ and $7 \%$ respectively. The optimal medical management of resistant duodenal ulcers has not yet been standardised although the efficacy of mucosal protecting agents has been recently suggested. ${ }^{16}$ This controlled trial shows that TDB significantly speeds up the healing process of resistant ulcers. Indeed, the healing rate at four weeks was significantly higher on TDB $(82 \%)$ than on cimetidine $1.2 \mathrm{~g}(39 \%)$ and on cimetidine $2 \mathrm{~g}(44 \%)$. After eight weeks, TDB cure rate $(94 \%)$ was again numerically superior to those of both cimetidine schedules $(65 \%$ and $75 \%$ respectively), but only when compared with the lowest dose the difference reached statistical significance. These findings confirm, therefore, the view that resistant duodenal ulcers are more responsive to an agent which strengthens the mucosal defences than to an antisecretory compound ${ }^{b}$ and suggest the hypothesis that in the pathogenesis of this type of ulcer a weakening of the protective capacity of the mucosa

Table 3 Endoscopic evaluation of ulcer healing after 4 and 8 weeks. In parentheses are reported the $95 \%$ confidence intervals for the differences

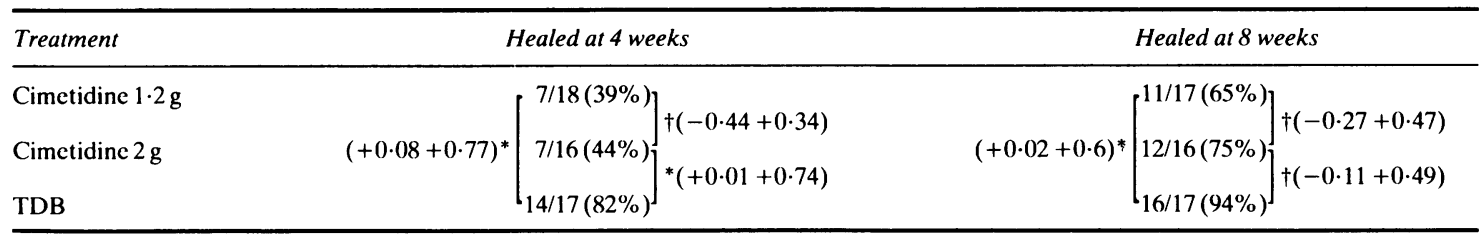

${ }^{*} \mathrm{p}<0 \cdot 05 ; \mathrm{tpns}$. 


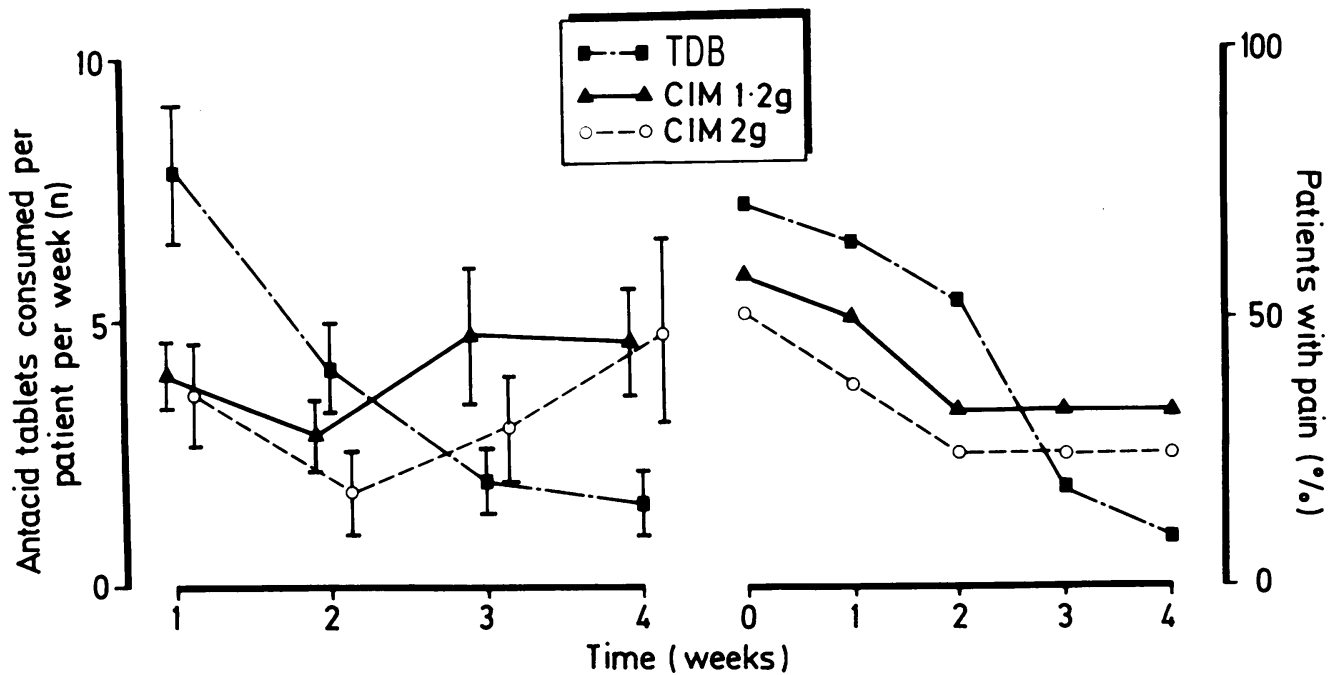

Figure Antacid consumption (mean $\pm S E M$ ) and pain behaviour in the three treatment groups during the first month of therapy.

plays a more important role than aggressive peptic forces. Likewise $\mathrm{H} 2$-blockers, TDB is known to heal approximately $90 \%$ of duodenal ulcers within eight weeks, ${ }^{17}$ thus it should be worth evaluating whether cimetidine heals those $10 \%$ of ulcers that do not respond to an initial course of TDB.

Regarding the possible usefulness of higher $\mathrm{H} 2$ antagonist dosage, as suggested by uncontrolled studies, ${ }^{45}$ our work documents the lack of a clear advantage in increasing the dose of cimetidine in patients with resistant ulcers. In fact, among those continuing $\mathrm{H} 2$-blocker treatment any further healing appeared due to the length of therapy itself rather than to the dosage used; this compares well with that observed in 'responder' duodenal ulcers, in which the $2 \mathrm{~g}$ dose of cimetidine was not found to be more effective than the standard $1 \mathrm{~g}$ dose. ${ }^{18}$

The failure of the higher cimetidine dosage to improve the healing rate of the lower dose could be explained by the observation that in cimetidine nonresponders increasing the dosage from 1 to $2 \mathrm{~g}$ daily did not result in any further increment of acid inhibition. $^{19}$

In conclusion, two sets of information can be drawn from this study: first, when $\mathrm{H} 2$-blockers fail to heal a duodenal ulcer within eight weeks, TDB should be the treatment of choice because it expedites the further healing process; second, many of these so called 'resistant' ulcers may be expected to heal simply by prolonging $\mathrm{H} 2$-antagonists administration provided that enough time - that is, eight weeks, is given. In the latter case the standard dosage appears to be the most suitable regimen.
This work was presented in part at the spring meeting of the British Society of Gastroenterology in Lancaster, and published in abstract form (Gut 1986; 27: 612-3).

\section{References}

1 Wormsley KG. Short-term treatment of duodenal ulceration. In: Baron $\mathrm{JH}$, ed. Cimetidine in the $80 \mathrm{~s}$. Edinburgh: Churchill Livingstone, 1981: 3-8.

2 Kerr GD. H2-receptor antagonists and duodenal ulcer healing: the international experience. In: Cohen SC, ed. Update: H2-receptor antagonists. New York: Biomedical Information Corporation, 1984: 69-74.

3 Bardhan KD. Non-responders to cimetidine treatment. Part 2. In: Baron JH, ed. Cimetidine in the $80 \mathrm{~s}$. Edinburgh: Churchill Livingstone, 1981: 42-57.

4 Bardhan KD. Refractory duodenal ulcer. Gut 1984; 25: 711-7.

5 Bardhan KD. Refractory duodenal ulcer: a review. In: Bianchi Porro G, Bardhan KD. eds. Topics in peptic ulcer disease. New York: Raven Press. 1987.

6 Lam SK, Lee NW, Koo J, Hui WM, Ng M. Randomized crossover trial of tripotassium dicitrato bismuthate versus high dose cimetidine for duodenal ulcers resistant to standard dose of cimetidine. Gut 1984; 25: 703-6.

7 Guslandi M. More about refractory duodenal ulcers. Gut 1984; 25: 1433.

8 Quatrini M, Basilisco G, Bianchi PA. Treatment of cimetidine resistant chronic duodenal ulcer with ranitidine or cimetidine: a randomized multicentre study. Gut 1984; 25: 1113-7.

9 Amouretti M, Ansenay M, Bader J-P, et al. Efficacitè de la ranitidine et de la cimetidine dans le traitement de lulcere duodenal ou gastrique resistant a un traitement 
initial par la cimetidine. Essai therapeutique controlè multicentrique. Gastroenterol Clin Biol 1985; 9: 147-52.

10 Mazzacca G, D'Agostino L, D'Arienzo A, Piai G, Sabbatini F, Verre C. Cimetidine or ranitidine nonresponder patients: treatment of duodenal ulcers resistant to one $\mathrm{H} 2$ blocker with the other [Abstract]. Scand J Gastroenterol 1982; 17: suppl 78: 408.

11 Witzel L, Wolbergs E: Peptic ulcer healing with ranitidine in cimetidine resistant. Lancet 1982; 2: 1224.

12 Bianchi Porro G, Petrillo M, De Nicola C, Lazzaroni M. A double-blind endoscopic study with De Nol tablets and cimetidine for duodenal ulcer. Scand J Gastroenterol 1984; 19: 905-8.

13 Petrillo M, Prada A, Grossi E, Bianchi Porro G. Trattamento con cimetidina dell'ulcera duodenale attiva: quattro od otto settimane? In: Lucchelli P, ed. Cimetidina, farmacologia e clinica. Welwyn: Smith Kline \& French, 1978: 157-63.

14 Bianchi Porro G, Barbara L, Cheli R, Dal Monte PR, Mazzacca G. Comparison of tripotassium dicitrato bismuthate (TDB) tablets and ranitidine in healing and relapse of duodenal ulcers [Abstract]. Gut 1984; 25: A565.

15 Parente F, Carrara M, Comin U, et al. Monodose serale di ranitidina nella terapia a breve termine dell'ulcera duodenale. Uno studio multicentrico controllato in doppio cieco. Rec Prog Med 1985; 77: 154-7.

16 Pounder RE. Duodenal ulcers that will not heal. Gut 1984; 25: 697-702.

17 Barbara L, Corinaldesi R, Rea E, Paternicò A, Stanghellini $\mathrm{V}$. The role of colloidal bismuth subcitrate in the short-term treatment of duodenal ulcer. Scand J Gastroenterol 1986; 21: suppl 122: 30-4.

18 Bardhan KD, Saul DM, Edwards JL, et al. Comparison of two doses of cimetidine and placebo in the treatment of duodenal ulcer: a multicentre trial. Gut 1979; 20: 68-74.

19 Gledhill T, Buck M, Mc Ewan J, Paul A, Hunt RH. Effect of cimetidine $1 \mathrm{~g} /$ day and cimetidine $2 \mathrm{~g} /$ day on nocturnal intra-gastric acidity and acid secretion in cimetidine non-responders [Abstract]. Gut 1982; 23: A454. 